\title{
Gênero, ciência e etnografia digital: aproximações e potencialidades
}

\author{
JÚlia VARGAS BATISTA \\ Universidade Federal de Minas Gerais, Belo Horizonte, Minas Gerais, Brasil \\ juliavargasb.jv@gmail.com \\ ÉRICA RENATA DE SOUZA \\ Universidade Federal de Minas Gerais, Belo Horizonte, Minas Gerais, Brasil \\ erica0407@gmail.com
}

DOI 10.11606/issn.2316-9133.v29i2pe175199

resumo Considerando que a dicotomia online/offline não é capaz de contemplar as articulações e experiências de gênero e sexualidade em rede, uma vez que as fronteiras entre material/virtual podem se mesclar e repercutir entre si, este artigo discute o fazer etnográfico a partir da revisão de pesquisas de gênero e sexualidade em diálogo com a Antropologia da Ciência e da Tecnologia. O objetivo central deste artigo é refletir sobre as possibilidades etnográficas que vêm sendo empregadas a partir do debate das redes de produção de ciências, tecnologias e saberes que propiciam a produção de gêneros e sexualidades e, portanto, de novos corpos e sujeitos. No intuito de mapear o que vem sendo discutido mais recentemente no cenário nacional, essa pesquisa teve foco nos anais de dois grandes eventos brasileiros (ReACT e RBA). Mais de 50 trabalhos foram identificados e analisados. Temas como hormonização e transsexualidade, experiências de maternidade, ciberfeminismos e ativismo nas redes, experiências relacionadas ao HIV, entre outros, foram bastante frequentes, e algumas abordagens etnográficas também foram identificadas. Assim, buscamos refletir sobre os desafios e caminhos possíveis para o fazer etnográfico cada vez mais tecnologicamente situado.

palavras-chave Gênero; Sexualidade; Etnografia; Antropologia da Ciência e da Tecnologia; Etnografia digital.

\section{Gender, Science and digital ethnography: approaches and similarities}

abstract The article discusses ethnographic research based on a review of gender and sexuality works in dialogue with the Anthropology of Science and Technology. Its premise is that online/offline dichotomy is not able to contemplate the articulations and 
experiences of gender and sexuality in a network, since the boundaries between material/ virtual can blend and resonate with each other, this article. The central objective of this article is to reflect on the ethnographic possibilities that have been used since the debate on the production networks of sciences, technologies and knowledge that provide the production of genders and sexualities and, therefore, of new bodies and subjects. In order to map the more recently discussions on the national scene, this research focused on the annals of two major Brazilian events (Meeting of the Anthropology of Science and Technology and the annual meeting of the Brazilian Anthropological Association). It identified and analyzed more than 50 papers. Themes such as hormonization and transsexuality, experiences of motherhood, cyberfeminisms and activism in networks, experiences related to HIV, among others, were quite frequent, and we identified some ethnographic approaches as well. Thus, we seek to reflect on the challenges and possible paths for ethnographies increasingly technologically situated.

keywords Gender. Sexuality. Ethnography. Anthropology of Science and Technology. Digital Ethnography.

\section{Género, ciencia y etnografía digital: acercamientos y potencialidades}

resumen Considerando que la dicotomía online/offline no es capaz de contemplar las articulaciones y experiencias de género y sexualidad en red, ya que los límites entre lo material/virtual pueden fusionarse y resonar entre sí, este artículo trata de la elaboración etnográfica a partir del examen de la investigación sobre género y sexualidad en diálogo con la Antropología de la Ciencia y la Tecnología. El objetivo principal de este artículo es reflexionar sobre las posibilidades etnográficas que se han empleado a partir del debate de las redes de producción de ciencias, tecnologías y conocimientos que propician la producción de géneros y sexualidades y, por tanto, de nuevos cuerpos y sujetos. Con el fin de mapear lo que se ha discutido más recientemente en la escena nacional, esta investigación se centró en los anales de dos grandes eventos brasileños (ReACT y RBA). Se identificaron y analizaron más de 50 obras. Temas como la hormonización y la transexualidad, las experiencias de maternidad, el ciberfeminismo y el activismo en redes, las experiencias relacionadas con el VIH, entre otros, fueron bastante frecuentes, y también se identificaron algunos enfoques etnográficos. Así pues, tratamos de reflexionar sobre los desafíos y las posibles formas de hacer que la etnografía se sitúe cada vez más tecnológicamente.

palabras clave Género. Sexualidad. Etnografía. Antropología de la Ciencia y Tecnología. Etnografía digital. 


\section{Introdução}

As intersecções entre gênero, sexualidade, ciência e tecnologia vêm produzindo importantes contribuições à antropologia e várias outras disciplinas nas últimas décadas. Como aponta Nucci (2015a), no cenário internacional, é no final dos anos 1970 e início dos anos 1980 que os estudos feministas e os estudos sociais da ciência começam a dialogar (NUCCI 2015a: p.34). No Brasil, contudo, essa articulação já é mais tardia, ganhando expressividade a partir dos anos 1990. Acompanhando o crescimento do campo da Antropologia da Ciência e da Tecnologia (ACT), sobretudo desde 2010 (ROHDEN; MONTEIRO 2019), as abordagens sobre gênero e sexualidade dentro da Antropologia da Ciência e da Tecnologia vêm sendo bastante discutidas no Brasil. Nesse sentido, buscamos os trabalhos mais recentes para pensar quais as temáticas e abordagens teóricometodológicas vêm sendo utilizadas, numa tentativa de melhor compreender este campo de estudo.

Inserida no projeto "O antropólogo no campo e na rede: o fazer etnográfico em pesquisas de gênero e sexualidade”, nossa investigação teve início em julho de 2018 e se propunha a problematizar o fazer etnográfico a partir dos estudos de gênero e sexualidade. Compreendendo que a dicotomia online/offline não seria capaz de contemplar as articulações e experiências de gênero e sexualidade em rede, uma vez que as fronteiras entre material/virtual podem se mesclar e repercutir entre si (MILLER; SLATER 2004; LEITÃO; GOMES 2017), pensar os trabalhos cujos projetos etnográficos se deram em redes e plataformas digitais foi especialmente interessante à pesquisa. O objetivo central deste artigo é refletir sobre as possibilidades etnográficas que vêm sendo empregadas a partir do debate das redes de produção de ciências, tecnologias e saberes que propiciam a produção de gêneros e sexualidades e, portanto, de novos corpos e sujeitos.

A Antropologia da Ciência e da Tecnologia, no Brasil, vem se consolidando nas últimas a partir de diversas abordagens temáticas e importantes reflexões relacionadas a questões chave dentro da antropologia, desde as clássicas discussões sobre natureza e cultura, humanos e não humanos, até debates mais recentes, como os estudos sobre as ciberculturas e ambientes digitais (ROHDEN; MONTEIRO 2019).

Quanto às abordagens teórico-metodológicas, destaca-se a ideia da ciência e tecnologia como produto de complexas redes de associações e articulações heterogêneas (Callon, 1987), de modo que se torna inconcebível a manutenção de proposições analíticas calcadas em distinções como natural e cultural ou material e produzido (Latour e Woolgar, 1997; Law, 2009). A inspiração vem não só da própria teoria antropológica, como também dos estudos sociais da ciência e da tecnologia (Martin, 1998; Fischer, 2007) e da crítica feminista da ciência (Haraway, 1989). Nesse último caso, a influência dos estudos 
antropológicos de gênero e a necessidade de reconhecer a situacionalidade do conhecimento científico, bem como a problematização da ideia de natureza contida nos pressupostos biológicos em torno da produção da diferença sexual e racial, já há muito fomentavam a análise crítica (ROHDEN; MONTEIRO 2019: p. 2-3).

Como afirmou Monteiro em 2012, "os estudos feministas e de gênero, que foram pioneiros em abordar a tecnologia e sua relação com corpos, processos biológicos e relações de poder" (MONTEIRO 2012: p.143). Além disso, "as teorias feministas têm sido fonte de inspiração para os ESCT, e hoje são tidas como parte importante daquilo que se considera o campo de estudos de ciência, assim como da própria antropologia" (MONTEIRO 2012: p.144). Nesse sentido, discussões trazidas pelos estudos de gênero foram essenciais para a constituição da Antropologia da Ciência e da Tecnologia sendo essa articulação entre gênero, sexualidade, ciência e tecnologia um campo bastante profícuo dentro da antropologia.

Trata-se da produção de uma abordagem que combina teoria antropológica, estudos feministas da ciência e estudos sociais da ciência e da tecnologia na análise etnográfica das chamadas ciências da vida por meio de suas interfaces com a dimensão do gênero e outros marcadores, especialmente a sexualidade. A área das biociências, de modo geral, encarnada em ramos como genética, medicina reprodutiva, medicina sexual, endocrinologia, neurociências, tem sido estudada tanto nas suas redes de produção quanto nos seus variados usos cotidianos nas vidas concretas das pessoas (ROHDEN; MONTEIRO 2019: p.13).

Além do enfoque biomédico, os estudos de gênero em articulação à ACT trazem várias outras abordagens, como já dito. Os estudos sobre ciberfeminismos e questões de gênero nas redes digitais, e também importantes discussões e críticas à própria produção da ciência de modo mais amplo - sobretudo no que se refere à hegemonia masculina dentro dos campos científicos em termos de produção e de reconhecimento, pautando a valorização da produção de mulheres - são algumas dessas possibilidades.

Para a história e para a política das ciências, ainda é premente a necessidade de se reconhecer e valorizar a participação e a produção de mulheres e a forma como relações desiguais, simbologias e estereótipos de gênero foram incorporados e reproduzidos nas práticas e instituições científicas, ignorando as dimensões raciais e étnicas, influenciando até hoje as carreiras de mulheres e homens, os valores e a forma de organização dessas instituições (LOPES; SOMBRIO 2017: p.2). 
Assim, no intuito de mapear o que vem sendo discutido mais recentemente no cenário nacional articulando gênero, sexualidade, ciência e tecnologia, essa pesquisa teve foco nos anais desses dois grandes eventos brasileiros (ReACT e RBA). Os eventos foram selecionados devido à sua importância nacional e ao grande número de trabalhos apresentados em seus Grupos de Trabalho e Simpósios Temáticos. Dessa forma, buscou-se identificar as temáticas e discussões trazidas pelos trabalhos sobre a articulação entre gênero e ciência, bem como as abordagens etnográficas utilizadas, sendo possível identificar também divergências e convergências em relação aos dados aferidos pela pesquisa anterior (GONÇALVES 2018). Em acordo com Rohden e Monteiro (2019) ao trazerem um panorama sobre o que vem sendo discutido na ACT no Brasil, eixos temáticos como biomedicina e distinções sexuais, intervenções corporais e acesso à saúde, expressões no ciberespaço, etc. também foram fortemente identificados nos trabalhos aqui analisados. Nesse sentido, nos propusemos a analisar textos publicados em anais de dois grandes eventos brasileiros: a Reunião Brasileira de Antropologia (RBA) e a Reunião de Antropologia da Ciência e da Tecnologia (ReACT). Os resultados de Gonçalves (2018) apontaram um reduzido número de trabalhos que fossem realizados a partir de pesquisa de campo virtual, o que pode nos dizer muito sobre a própria concepção de etnografia:

Deve-se repensar qual o estatuto que o trabalho antropológico exerce quando se volta para o estudo de seu "próprio mundo", tendo em vista que os trabalhos aqui analisados continuam com uma visão exotizada do trabalho etnográfico, tentando estabelecer em grande medida uma produção de um outro, deslocando o eu para fora desse contexto que se analisa, no qual muitas vezes não faz sentido. (GONÇALVES 2018).

Assim, buscamos investigar os pontos de fricção e de articulação em etnografias que se propõem a articular gênero e ciência a partir dos trabalhos apresentados nos eventos ReACT e RBA.

\section{Metodologia}

A metodologia desta pesquisa consistiu, inicialmente, no levantamento dos trabalhos que abordassem as temáticas de gênero e ciência apresentados nas últimas edições da Reunião de Antropologia da Ciência e Tecnologia (React) e da Reunião de Antropologia Brasileira (RBA). Como já mencionado, os eventos foram escolhidos devido à sua importância no cenário nacional em relação às áreas de interesse da pesquisa (gênero, antropologia, ciência e tecnologia), além do fato de que ambos recebem um grande número de trabalhos, permitindo uma maior amostragem. Além disso, a análise de anais de eventos permite-nos rastrear os trabalhos mais recentes, muitas vezes frutos de pesquisas ainda em desenvolvimento, produzidos em grande parte por jovens pesquisadores, estudantes de pósgraduação e de graduação em formação. Duas edições recentes de cada um dos eventos foram 
contempladas pela pesquisa, sendo as edições de 2015 e de 2017 da ReACT, e de 2016 e 2018 da RBA. Em seguida, foram analisados os anais dos Simpósios Temáticos - STs - (React) e dos Grupos de Trabalho - GTs - (RBA) que trazem as temáticas "gênero" e/ou "sexualidade" e/ou "ciência" e/ou "tecnologia" (ou termos afins) nos títulos. No caso da ReACT, por se tratar de um evento específico de Antropologia da Ciência e Tecnologia, os STs foram filtrados somente pela presença das temáticas de "gênero", "sexualidade" e afins. Dentro de cada GT e ST, foram localizados, por meio dos títulos e/ou dos resumos, trabalhos que articulam os temas de gênero, sexualidade, ciência, tecnologia, mesmo que a partir de diferentes abordagens metodológicas e etnográficas. Em primeiro momento, os trabalhos selecionados (cf. Documento suplementar) foram analisados e fichados e, em seguida, classificados de acordo com as abordagens etnográficas utilizadas. É importante mencionar que os textos completos de alguns trabalhos não estavam disponíveis.

A ReACT e a RBA foram selecionadas devido à sua importância nacional para a Antropologia. A RBA, em sua 31ª edição em 2018, teve sua primeira realização em 1953, na cidade do Rio de Janeiro, antes mesmo da fundação da Associação de Antropologia Brasileira - ABA. Desde então, as diretorias da ABA eleitas em cada edição da RBA organizam o próximo evento, no qual será eleita uma nova diretoria. Em 2016, a RBA, realizada em João Pessoa - PB, contou com mais de 1800 participantes. A última edição do evento foi em dezembro 2018, realizada na UnB, em Brasília - DF. A React, Reunião de Antropologia da Ciência e Tecnologia, teve a sua última edição realizada em maio de 2019, na Universidade Federal de Santa Catarina, em Florianópolis-SC. O evento está em sua sétima edição e se destaca no cenário nacional das discussões sobre antropologia, ciência e tecnologia. As edições de 2015 e 2017, analisadas nesta pesquisa, foram realizadas em Porto Alegre - RS e em São Paulo - SP, respectivamente.

Ao todo, compreendendo os quatro eventos, foram identificados 55 trabalhos que articulam as temáticas gênero, sexualidade, ciência e tecnologia em onze STs/GTs. É importante reiterar que essa seleção foi feita com base nas palavras-chave dos títulos e resumos presentes nos GTs e STs. Desse modo, é possível que outro(s) trabalho(s) compatível(is) não tenham sido contemplados nesta análise.

\begin{tabular}{|c|c|c|c|c|}
\hline Evento & Ano & $\begin{array}{c}\text { Número total } \\
\text { de STs/GTs }\end{array}$ & $\begin{array}{c}\text { Número de STs/GTs } \\
\text { correspondentes }\end{array}$ & $\begin{array}{c}\text { Número de } \\
\text { trabalhos } \\
\text { correspondentes }\end{array}$ \\
\hline V React & 2015 & 09 & 01 & 03 \\
\hline VI React & 2017 & 24 & 02 & 08 \\
\hline $30^{\text {a }}$ RBA & 2016 & 64 & 03 & 19 \\
\hline $31^{\text {a }}$ RBA & 2018 & 66 & 05 & 25 \\
\hline
\end{tabular}


Tabela 1. Relação de trabalhos e STs/GTs identificados como correspondentes às temáticas da pesquisa por evento e ano. Dados das autoras, 2020.

$\mathrm{Na}$ ReAct 2015, dentre um total de nove STs, foram identificados apenas três trabalhos que correspondiam ao escopo da pesquisa em somente um ST, denominado "ST8 - Corporalidades, Saberes e Tecnologias”. Já na React 2017, identificou-se trabalhos em dois STs, "ST 8 - (Co)produções contemporâneas: Intervenções biotecnológicas sobre o corpo, gênero e sexualidade" (06 trabalhos) e "ST 17 - Políticas etnográficas no campo da cibercultura” (02 trabalhos), num universo de 24 STs. Já na RBA 2016, foram identificados três GTs que correspondem às temáticas: "GT010. Antropologia Digital, Tecnologia e Cibercultura", "GT049. Partos e/ou maternidades e políticas do corpo: perspectivas antropológicas"; e "GT052. Políticas Etnográficas no Campo da Cibercultura”, totalizando 19 trabalhos. Contudo, não foi identificado nenhum trabalho que articulasse as temáticas em questão no GT052. Na RBA 2018, foram identificados 25 trabalhos dentre cinco GTs: "GT 021 - Antropologia e tecnociência: teorias, métodos e perspectivas"; "GT 023 - Antropologia, gênero e saúde no contexto neoliberal e neoconservador no Brasil: desafios e estratégias de enfrentamento"; "GT 040 - Fronteiras, saúde, gênero e sexualidade: conexões, deslocamentos e alteridades corporais, espaciais, temporais”; "GT 042 - Maternidades, partos e cuidado infantil: políticas dos corpos, direitos humanos e antropologia em ação"; e "GT 057 - Processos e dinâmicas no ciberespaço: divergências, dissidências, usos e contra-usos em relação à experiência de si”.

\section{Mapeando os temas das pesquisas}

Como já mencionado, a Antropologia da Ciência e da Tecnologia, em articulação às discussões de gênero e sexualidade, permite inúmeras abordagens e temas possíveis, desde o debate em torno da biologia e dos hormônios sexuais - ou o que Monteiro (2012) chama de "questão da compreensão do conhecimento científico sobre corpos e biologia como instrumento de naturalização das desigualdades e hierarquias de gênero" (MONTEIRO 2012: p.144) - até as discussões sobre ciberfeminismos e articulação política nas redes online. Ao identificar os trabalhos analisados na pesquisa, também foi possível notar essa diversidade de temas e abordagens. Alguns discutem, por exemplo, o acesso à saúde e experiências sobre o HIV, trazendo referências dos estudos de gênero e sexualidade, como os trabalhos "O parentesco conformado na experiência soropositiva: Uma abordagem antropológica sobre a transmissão vertical para o HIV na perspectiva crítica dos estudos de gênero", de Ricardo Andrade Coitinho Filho e "Entre revoluções sexuais e ferramentas de prevenção: uma narrativa sobre a emergência da Profilaxia Pré-Exposição (PrEP)”, de Felipe Cavalcanti Ferrari - apresentados na ReAct 2017 - e "Mediação e moralidades sobre medicamentos de gênero: A implementação das Profilaxias Pré-Exposição ao HIV num hospital da rede pública do Natal-RN", de Antônio Ricardo Ximenes de Araújo - RBA 2018. De acordo com Rohden e Monteiro (2019), um dos possíveis eixos dentro da ACT para 
pensar as aplicações e os impactos da ciência da e na vida das pessoas é a discussão acerca dos processos de "medicalização e à farmaceuticalização de condições humanas, pensadas no quadro de processos globais envolvendo redes variadas e complexas" (ROHDEN; MONTEIRO 2019: p.11). Tais processos estão muitas vezes intimamente relacionados a questões concernentes ao gênero e à sexualidade, como, inclusive, a esfera terapêutica em torno do HIV/AIDS "e suas repercussões nos âmbitos de governo, mercados, sistemas de saúde e vida pessoal, chamando a atenção para as singularidades dos contextos e das vidas concretas das pessoas" (ROHDEN; MONTEIRO 2019: p.11-12).

O trabalho de Ricardo Andrade Coitinho Filho (2017), por exemplo, aponta como a interseccionalidade é importante para compreender os processos sociais relacionados à transmissão do HIV ao tratar de uma etnografia realizada junto a uma rede de acolhimento de jovens soropositivos no Rio de Janeiro. O objetivo do trabalho é

[relacionar] a forma como a temática da transmissão vertical tem tido aparições na etnografia realizada numa 'rede' de jovens soropositivos, mediante a discursos médicos e experienciais, à crítica dos estudos de gênero, que potencializam o debate antropológico acerca do parentesco (FILHO 2017: p. 58).

A partir das experiências de algumas interlocutoras mães que participam dessa rede, o trabalho discute como a medicalização dos corpos se relaciona à produção de discursos sobre saúde e a possibilidade de maternidade para mulheres soropositivas. Segundo o autor, "há que se considerar que falar de transmissão vertical para o HIV é falar sobre gênero, sexualidade, corpo e reprodução. Neste sentido, há todo um aparato científico intervencionista voltado para a mulher soropositiva mais que em relação a homens" (FILHO 2017: p.66).

Este trabalho se relaciona também a uma das temáticas mais frequentes entre os textos identificados, que consiste, de modo geral, nas discussões sobre maternidade, parturição e gestação. Os trabalhos trazem diferentes abordagens e nos mostram a multiplicidade de possibilidades dentro dessa área, como a questão da violência obstétrica e as intersecções entre gênero, classe e raça no trabalho "As Vozes que gritam tem cor: Violência Obstétrica e o Impacto na vida das Mulheres Negras”, de Ana Claudia Coutinho da Silva e Cintía de Souza Batista Tortato (RBA 2018); as relações de cuidado e corporalidades em contextos indígenas trazidas por trabalhos como "Nascer Xakriabá: técnicas do corpo e cuidado antes e após o nascimento" de Érica Dumont Pena e Rogério Correia (RBA 2016); as discussões sobre parto humanizado, como no texto "Compreensões e papéis da tecnologia no ideário do parto humanizado”, de Camila Pimentel (RBA 2018); o debate em torno do Zika Vírus, seus impactos e desafios enfrentados por mães e filhos que convivem com a microcefalia, sobretudo na região nordeste do país, como trazido pelos trabalhos "Gênero e saúde em contexto de duplo fazer: as respostas ao Zika vírus no Brasil" 
de Jonatan Jackson Sacramento e Maria Conceição da Costa, e "Zika Vírus e Síndromes Congênitas: Impacto da Epidemia em Mulheres 'Mães de Micro' no RN em um contexto pós-golpe", de Rozeli Maria Porto; e ainda trabalhos como "Por quê o parto se tornou uma questão?", de Sara Sousa Mendonça e "Maternidade, gênero e ciência: reflexões e tensionamentos", de Marina Fisher Nucci, que trazem revisões sobre os debates em torno de temas como maternidade, parto, corporalidades, discursos médicos, e parturição, articulando contribuições e tensões entre ciência, feminismo e empoderamento.

Esses trabalhos indicam a miríade de abordagens possíveis sobre como a esfera da ciência e das tecnologias se relacionam à maternidade e ao ciclo gravídico-puerperal, possibilitando uma série de apropriações e inovações seja em relação às intervenções corpóreas e processos de medicalização, seja em relação aos procedimentos de parto, ao debate em torno da humanização, ao entendimento sobre violência obstétrica, aos múltiplos desafios da maternidade durante e após o puerpério, às redes de apoio e cuidado, aos constructos sociais em torno do ideal de maternidade, etc. Os trabalhos que tratam da questão do Zika Vírus e suas consequências às famílias afetadas, por exemplo, nos mostra não somente as dificuldades de acesso às tecnologias terapêuticas, mas também os desafios políticos enfrentados perante as instituições públicas e os sistemas de saúde, as apropriações e manejos do conhecimento científico, e as redes de apoio e cuidado que vão se consolidando em torno da realidade dos corpos ali envolvidos, sempre em diálogo com as relações de afeto e maternagem. Além disso, pensar os diferentes saberes e as intersecções de classe, raça e regionalidade permeadas nesses processos é de grande importância nesse cenário, ao considerar, por exemplo, os acessos e usos das tecnologias reprodutivas e de parturição.

É importante reiterar que todas essas discussões vêm, em grande medida, ancoradas à base da relação entre a ACT e os estudos de gênero e sexualidade, que, como apontam Rohden e Monteiro (2012), é resultado da articulação entre a crítica feminista à produção científica e os estudos sobre a própria ciência.

Esses estudos têm produzido uma análise crítica da produção científica moderna acerca das supostas bases naturais e imutáveis que determinariam sexo, gênero e sexualidade. De maneira especial, as ciências biomédicas têm sido profícuas em redesenhar variadas formas de "substancialização" da diferença, em contornos dualistas inspirados pela oposição natureza/cultura (Rohden, 2008) (ROHDEN; MONTEIRO 2012: p.12).

Nesse sentido, as discussões acerca dos hormônios e distinções sexuais, tema chave no debate de gênero e sexualidade na ACT, foram trazidas pelos trabalhos aqui analisados também sob diferentes contextos, como em relação aos processos de hormonização de pessoas transexuais, a produção de anticoncepcionais e as relações de gênero, e aos debates em torno dos discursos científicos sobre as distinções sexuais entre "corpos femininos" e 
"corpos masculinos", como nos textos "Intersexualidades e Biotecnologias: um estudo antropológico acerca da inserção da Hiperplasia Adrenal Congênita no Teste do Pezinho", de Janaína Freitas, "Hormonioterapia e a adequação de gênero no processo transexualizador", de Anderson Santos Almeida, "Corpo hormonal feminino e suas fases", de Regina Senna Vieira e Miriam Oliveira Mariano, apresentados na ReAct 2015. Neste evento também foi apresentado o trabalho “'Não chore, pesquise!' - Reflexões sobre sexo, gênero e ciência a partir do neurofeminismo", também de Marina Fisher Nucci, que trata das "relações entre sexo, gênero, ciência e feminismo, a partir da análise da produção e crítica contemporânea das neurofeministas da rede NeuroGenderings" (NUCCI 2015b: p.4). Foram apresentados também os textos "Corpo de monstro, mente de cientista': contradições nos discursos médicos e leigos acerca do uso da testosterona como anabolizante muscular" de Lucas Tramontano e "Não afeta a libido!: reflexões sobre hormônios e a construção da viabilidade de contraceptivos masculinos" de Georgia Pereira e Rogerio Lopes Azize. Na RBA 2018 também foi apresentado o trabalho "Os hormônios contraceptivos entre antigas e novas controvérsias: (re)negociações em torno de contracepção, gênero e saúde" de Bruna Klöppel, por exemplo, que também aborda discussões sobre hormônios contraceptivos e as relações de gênero e sexualidade. Tais discussões estão em consonância ao debate mais amplo dentro da Antropologia da Ciência e da Tecnologia, sobretudo no que se refere às distinções sexuais e ideais de gênero e à crítica feminista em torno do conhecimento científico localizado (HARAWAY 1995; LOPES; SOMBRIO 2017).

Essa atenção acerca de como a produção biomédica tem sido insistente na delimitação da diferença entre os gêneros e nas prescrições sobre as sexualidades permitidas ou condenadas tem sido marca importante nessa linha da ACT. Além disso, as investigações em torno dos hormônios, e mais especialmente no que se refere à conformação de uma preeminência da lógica hormonal como metáfora de entendimento do humano (Oudshoorn, 1994; Roberts, 2007; Rohden, 2008), têm sido profícuas (ROHDEN; MONTEIRO 2012: p.12).

Muitos dos trabalhos analisados (24 dentre os 55 inicialmente identificados) trazem questões relacionadas ao ciberespaço e às ciberculturas, sob diferentes perspectivas. Como aponta Grillo (2019), os estudos sobre a Internet ganharam interesse da antropologia principalmente a partir da segunda metade da década de 1990. Segundo este autor, muitas são as controvérsias a partir das quais o debate sobre as tecnologias digitais vem sendo construído dentro da disciplina. Autores como Christine Hine, Daniel Miller e Don Slater, Arturo Escobar, e Marilyn Strathern vêm especialmente fomentando este debate, sobretudo na primeira década do século XXI, a partir de suas posições e entendimentos sobre a Internet e as relações por elas mediadas (GRILLO, 2019). Em relação ao fazer etnográfico, Grillo (2019) destaca o trabalho de Miller e Slater (2004) sobre os cibercafés em Trinidad, que se 
configurou como uma grande contribuição aos estudos sobre esse campo na antropologia. Sobre isso, Grillo afirma:

Para la etnografía, afirman, la virtualidad no puede ser un punto de partida de la investigación etnográfica, sino un ítem más de problematización para explorar y explicar a la luz del universo de Itinerarios de la antropología y su mirada sobre el mundo digital prácticas desplegadas por los sujetos (GRILLO 2019: p.24-25).

Nesse sentido, é importante reiterar a necessidade de pensarmos as tecnologias e plataformas digitais como esferas plenamente etnográficas e que muito podem contribuir para a antropologia em geral, como nos mostram os textos dos anais aqui analisados. É interessante observar que muitos dos textos identificados na pesquisa também trazem a problematização do método etnográfico clássico em relação às etnografias virtuais, retomando as discussões da disciplina sobre trabalho de campo e etnografia. Em geral, os trabalhos apontam para a existência de um continuum entre o "mundo online" e o "mundo offline” (MISKOLCI, 2017 apud LEITÃO; GOMES, 2017), compreendendo que essas esferas não se desvinculam. Miller e Slater (2004), indicam a importância da "relação entre atividades on-line e off-line e, acima de tudo, em como os próprios participantes construíram distinções altamente diversas, complexas e fluidas entre suas vidas on-line e offline” (MILLER, SLATER 2004: p.47) para o fazer antropológico. Nesse sentido, é fundamental compreender a totalidade on e off-line na qual as relações estabelecidas em plataformas digitais/virtuais estão inseridas. Longe de se configurarem como neutras, as tecnologias digitais são cada vez mais conectadas às vidas das pessoas e à formação de subjetividades de diversas formas. Como afirmam Theophilos Rifiotis e Jean Segata (2016), "não por menos, esse campo tem sido dinâmico, desafiador, controverso e mobilizador de debates intensos em eventos e publicações" (SEGATA; RIFIOTIS 2016: p.9). Assim, apesar de convergirem em diversos aspectos, sobretudo teórico-metodológicos, os trabalhos analisados que se inserem na esfera do ciberespaço, das ciberculturas e das plataformas digitais pensando as relações de gênero e sexualidade abordam contextos e temas bastante distintos, desde o uso da internet para propagação e para denúncias de violências de gênero até relações de gênero e raça num espaço privativo entre participantes de um curso online, passando pela articulação política e feminista nas redes, debates públicos em sites e redes sociais, campanhas realizadas por meio do uso hashtags e muitos outros. Os desafios da empreitada etnográfica nesses contextos são apontados por muitas pesquisadoras. Beatriz Accioly Lins, por exemplo, em seu trabalho "Vazou na internet: gênero, violência e internet nos debates sobre "pornografia de vingança" aponta ter passado por "alguns desafios teóricometodológicos de conduzir uma pesquisa da e na internet, uma vez que boa parte dessa pesquisa se dá, em determinados espaços da própria rede, sejam sites de jornais e notícias, blogs feministas e redes sociais" (LINS 2016: p.1) e que 
[seguindo] as sugestões de Miller \& Slater (2004) de que seria necessário construir etnograficamente as múltiplas relações entre "on-line" e "offline”, penso fronteiras entre o real e o virtual sejam entendidas como contingentes, uma vez que, longe de serem esferas isoladas e autônomas, o "on-line" e o "off-line" estariam imersos em relações de continuidade (LINS, 2016, p. 9)

Dentre os textos analisados, abordagens sobre ciberfeminismos, movimentos sociais e internet como plataforma de mobilização foram trazidas em diversos trabalhos, como os textos "Múltiplas faces de um conceito de parto: uma abordagem etnográfica de grupos do Movimento de Humanização do Parto e Nascimento" de Lidiane Mello de Castro e Edemilson Antunes de Campos, “'Amanhã vai ser maior' (?): notas sobre os usos da internet nos (in)sucessos de duas manifestações de rua do ativismo de pessoas trans” de Mario Felipe de Lima Carvalho, e "Encriptando denúncias e revelando opressões: a internet enquanto plataforma para denúncias de violências de gênero e a agenda ciberfeminista” de Flora Villas Carvalho, por exemplo. Diversos debates nas redes sociais também foram analisados pelas pesquisas apresentadas, como nos trabalhos “Nem Presa, Nem morta': O debate sobre a descriminalização do aborto nas redes sociais durante a audiência pública no STF da ADPF 442" de Eliana Coelho da Silva e Alba Maria Pinho de Carvalho, "A Construção da Imagem Pública de Dilma Rousseff no Ciberespaço: Misoginia, estereótipos e relações de gênero” de Elizabeth Christina de Andrade Lima, "Ontologias Feministas no ciberespaço: discursos e contra discursos RadFem, de Fabiana Jordão Martinez, e "\#MaternidadeReal: conteúdo impróprio” de Clara Cazarini Trotta. Essas pesquisas evidenciam as discussões geradas em diferentes contextos no ciberespaço, que, como

[aponta] Lévy (1999, p. 224): "é um ambiente comunitário, transversal e recíproco", onde em tese, todos os sujeitos conectados estariam em potencial equilíbrio na relação, podendo exercer simultaneamente os papeis de 'emissor' e 'receptor' das informações em circulação na rede. Dito de outro modo, trata-se de um modelo dialógico, possibilitando o surgimento de um espaço propício de 'interação geral' a partir da interconexão e da criação de comunidades virtuais (LIMA 2016: p.3).

Nesse sentido, considerando o ciberespaço como local de interação e trocas, foi possível observar, por exemplo, a recorrência de trabalhos que abordam as relações entre mães nas redes sociais e suas interações em torno da maternidade, os desafios e possibilidades da experiência de ser mãe, como nos trabalhos "O desafio da maternidade': protagonismo feminino para além do parto” de Elaine Muller, "Grupo Papo de Mãe: uma experiência de rede de apoio à maternagem em Belém do Pará” de Natália Conceição Silva Barros 
Cavalcanti, e "Não me obriguem a um parto normal': Concepções de corpo e direito de escolha de mulheres gestantes que optam pela cesárea eletiva" de Jaqueline Cardoso Portela, apresentados na RBA 2016. Essas interações ganham destaque no cenário brasileiro e, como aponta Natália Cavalcanti (2016), é de grande importância refletir sobre o "papel pedagógico do que hoje posso nomear rede de apoio à maternagem, evidenciando os arranjos contemporâneos na concepção, definição e (con)formação do mulher grávida, puérpera e mãe" (CAVALCANTI 2016: p. 4).

Outros temas também foram abordados pelos trabalhos, como o uso de aplicativos móveis, softwares habilitados para dispositivos como smartphones e tablets. Os textos "Menstruapps e possíveis interseções entre corpo, tecnologia, política e gênero", de Gabriela Cabral Paletta (RBA 2018) e “Meu Tinder tá bombando!' Geolocalização, sociabilidade e vivências da sexualidade", de Sheila Cavalcante dos Santos (RBA 2016) se destacam nesse sentido. Apesar de tratarem de aplicativos com funcionalidades e objetivos bastante distintos, ambos nos apresentam importantes aspectos relacionados ao uso dessas plataformas digitais e suas agências sobre os corpos e as vivências da sexualidade e do gênero, problemantizando questões pungentes dentro dos estudos sobre ciberespaço, como o uso e gestão dos dados pessoais dos usuários.

Em síntese, observamos que as temáticas trazidas pelos trabalhos vêm, de certo modo, convergindo com o cenário mais amplo dos estudos de gênero e sexualidade dentro da Antropologia da Ciência e da Tecnologia no Brasil. Dentre esses temas, destacamos: As discussões em torno dos processos de hormonização e a crítica feminista sobre os preceitos hegemônicos da Ciência acerca das distinções sexuais e ideais de gênero; as múltiplas abordagens sobre as relações entre ciência, tecnologia e maternidade, parturição e gestação e como isso se conecta às questões de gênero; os processos de medicalização e acesso à saúde e tecnologias terapêuticas experienciados sob diversos contextos e possibilidades, como no caso das pessoas afetadas pelo Zika Vírus e pela microcefalia, ou mesmo pessoas que convivem com o vírus da imunodeficiência humana e com a Aids; o uso de aplicativos móveis e redes sociais para a consolidação de discursos, articulação política e formação de opinião, pensando as múltiplas vivências e expressões no ciberespaço e a diluição das fronteiras on/offline e os desafios teórico-metodológicos da etnografia em plataformas digitais.

\section{Sobre as escolhas etnográficas dos textos analisados}

Como já mencionado, as discussões sobre gênero, ciência e tecnologias trazem consigo uma série de questões em torno do fazer etnográfico e do lugar da antropologia perante as configurações e reconfigurações de gênero e sexualidade muitas vezes alinhadas aos usos e apropriações dos saberes científico-tecnológicos. Nesse sentido, um dos principais objetivos dessa pesquisa era identificar como as pesquisas mais recentes vêm tratando dessas questões de forma teórica e prática, ou seja, como as e os autores discutem o fazer etnográfico e como estão empregando as práticas etnográficas em suas pesquisas. Para além de pensar a 
etnografia como um método, o intuito aqui é compreendê-la, como nos instiga Mariza Peirano (2014), como formulações teórico-metodológicas, no sentido de considerar a experiência etnográfica e sua concretização em texto para além da mera descrição, trazendo reflexões e contribuições teóricas não somente para a antropologia, mas também para outros campos do conhecimento. "Etnografia não é método; toda etnografia é também teoria" (PEIRANO 2014: p.383).

Desse modo, pensando o campo da ciência e da tecnologia, sobretudo ao que se refere às pesquisas realizadas em e sobre plataformas digitais, é importante considerar que, como disciplina atenta à auto-reflexão, a antropologia deve ser capaz de se abrir a novas possibilidades de relações, comportamentos, experiências e também formas de se pesquisar. Como afirma Peirano (2014), "somos todos inventores, inovadores. A antropologia é resultado de uma permanente recombinação intelectual” (PEIRANO 2014: p.381). As múltiplas e inovadoras possibilidades que as relações mediadas pela tecnologia e pelos saberes científicos trazem consigo nos desafiam enquanto antropólogas e antropólogos a estar sempre atentos e abertos a novas configurações etnográficas. Apesar de recente em relação à história da antropologia, esse debate vem se consolidando já há algum tempo, talvez em consonância ao crescimento do interesse pelo estudo da cibercultura, que ganha destaque sobretudo nas últimas duas décadas (SEGATA; RIFIOTIS: 2016, p.9).

Numa tentativa de mapear as escolhas teórico-metodológicas utilizadas nos 55 trabalhos identificados analisados por nossa pesquisa, buscando também compreender como o ciberespaço e as plataformas digitais vêm sendo estudados, identificamos alguns "tipos" de etnografia, que aqui denominamos (de acordo com as descrições teórico-metodológicas de cada autor): etnografia online; etnografia presencial; etnografia em arquivos (notícias, matérias de jornal, documentos, leis etc.), etnografia online e presencial, e outros (revisão bibliográfica e ensaio fotográfico). A Tabela 2 indica o número de trabalhos que utilizaram cada tipo/possibilidade etnográfica.

\begin{tabular}{|c|c|}
\hline Tipo de etnografia & Número de trabalhos \\
\hline Etnografia online & 22 \\
\hline Etnografia presencial & 13 \\
\hline Etnografia em arquivos & 09 \\
\hline Etnografia online e presencial & 06 \\
\hline Outros (revisão bibliográfica, ensaio fotográfico, etc.) & 04 \\
\hline Não identificado & 01 \\
\hline
\end{tabular}

Tabela 2. Tipos de etnografia e número de trabalhos. Fonte: As Autoras, 2020. 
Dentre os 55 trabalhos que foram analisados, 22 foram realizados a partir de etnografia online exclusivamente. Destes, 18 tratam das ciberculturas e das plataformas digitais como temática central. Seis outros trabalhos utilizaram esse método conjuntamente à etnografia presencial. É interessante observar esse dado pois ele nos permite visualizar como as etnografias online se destacam no contexto dos trabalhos que articulam gênero, ciência, sexualidade e tecnologia mapeados por nossa pesquisa. Como sugerem Rohden e Monteiro (2019), o campo da cibercultura/antropologia digital no Brasil vem crescendo recentemente dentro da $\mathrm{ACT}$, agregando várias discussões sobre políticas etnográficas e uma série de outros temas (ROHDEN; MONTEIRO 2019).

Ao tratar mais especificamente dos estudos etnográficos em plataformas digitais, Leitão e Gomes (2017) trazem importantes apontamentos sobre possíveis caminhos que pesquisadores podem adotar para analisar contextos online/digitais. Para elas, ao pensar a pesquisa etnográfica, é preciso considerar as plataformas digitais como ambientes, espaços análogos aos cenários urbanos, com ruas, edificações, transeuntes, variados fluxos e dinâmicas. Segundo as autoras,

Algumas dessas áreas digitais, pelo tipo de socialidade que engendram, por sua topografia e seus ritmos particulares, exigem dos pesquisadores uma postura que se aproxima daquilo que Pétonnet (2008 [1982]) chamou de observação flutuante, tratando da pesquisa em ambientes urbanos: um deixar-se conduzir pelo inesperado, pelos encontros fortuitos, sem hora marcada, frequentando lugares de passagem sem um destino particular, enfatizar, enfim, os trajetos percorridos, mais do que os encontros já intencionalmente planejados com pessoas que já conhecemos previamente (LEITÃO; GOMES 2017: p.50)

Assim, é importante sempre considerar as experiências trazidas pelo campo de modo amplo, seguindo os fluxos e as possibilidades que são apresentadas aos pesquisadores. Como aponta James Clifford (2002),

A observação participante obriga seus praticantes a experimentar, tanto em termos físicos quanto intelectuais, as vicissitudes da tradução. Ela requer um árduo aprendizado linguístico, algum grau de envolvimento direto e conversação, e frequentemente um "desarranjo" das expectativas pessoais e culturais (CLIFFORD 2002: p.20).

No caso das plataformas digitais, com suas topografias e "ritmos particulares", a importância desse aprendizado e envolvimento também se torna muito evidente, posto que os fluxos de interação podem ser bastante particulares, intensos e dinâmicos. "Misturar-se ao ritmo dos demais transeuntes se coloca algumas vezes como profícua possibilidade para a participação dos pesquisadores nesses ambientes” (LEITÃO; GOMES, 2017, p. 51). Nesse 
sentido, Christine Hine ([2000] 2004) afirma que “[...] los etnógrafos se han lanzado a estudiar, bien contextos online, o bien offline. Para dar cuenta de Internet en ambas dimensiones: como cultura y como artefacto cultural es necesario repensar la relación entre espacio y etnografía” (HINE, [2000] 2004, p. 19; grifos nossos). Leitão e Gomes (2017) ainda sugerem considerar a etnografia plurilocal ou multissituada,

[...] que permitiria seguir o fluxo de pessoas, em se tratando de estudos migratórios, mas também de objetos e ideias. A diferença, que convém ressaltar, é que o pesquisador deve estar atento ao fato de que essas conexões que está perseguindo não são apenas agenciadas por seus interlocutores de pesquisa, mas resultado tanto das práticas destes quanto dos agenciamentos tecnológicos proporcionados pelos ambientes digitais (LEITÃO; GOMES 2017: p.54).

Assim, a partir da leitura dos trabalhos apresentados nas ReAct 2015 e 2017 e RBA 2016 e 2018, foi possível observar a tendência apontada por Leitão e Gomes (2017): "Seguindo a tradição disciplinar, a observação participante tem sido privilegiada na maioria dos trabalhos sobre mídias digitais, em detrimento de uma observação distanciada e anônima" (LEITÃO; GOMES 2017: p.48). Muitos dos trabalhos que analisamos foram realizados a partir de observação participante em grupos nas redes sociais, seja Facebook, Whatsapp, Twitter, Instagram etc., ou como no trabalho "Corpo de monstro, mente de cientista': contradições nos discursos médicos e leigos acerca do uso da testosterona como anabolizante muscular" de Lucas Tramontano, em que o autor realiza a pesquisa partindo principalmente de entrevistas online e da observação das relações e interações presentes em grupos de discussão e fóruns online, em que os participantes trocavam informações sobre como usar a testosterona, a quantidade, seus efeitos no corpo, contraindicações, compartilhando suas próprias experiências. Assim, o autor pôde mapear as histórias de vida de seus interlocutores, além de constatar a importância do ciberespaço para a construção dos discursos, usos e saberes da testosterona como anabolizante.

Exemplo interessante é também o trabalho "Interseção de gênero e raça num território privativo do ciberespaço" de Zelinda dos Santos Barros, em que a autora analisa as interações entre os participantes de um curso online sobre história e cultura afro-brasileira na plataforma Moodle, pensando as interseccionadas relações entre raça e gênero. A partir da observação participante (ministrante do curso) a autora busca discutir "como as categorias gênero e raça podem contribuir para explicar as diferenças na forma como homens e mulheres se relacionam com as tecnologias de informação e comunicação (TIC)” (BARROS, 2016: p.1). A autora discute como o ciberespaço é também permeado por uma série de desigualdades e marcadores sociais, como classe, gênero e raça, uma vez que se constitui como um espaço de interação. Corroborando as ideias trazidas por outros trabalhos aqui analisados, Barros aponta o vínculo existente entre as esferas online e offline, uma vez que 
as relações e interações empreendidas em ambos os espaços se conectam e repercutem entre si. Segundo ela,

Podemos não apenas investigar como ocorre a comunicação online como também os desdobramentos desta comunicação na vida offline, focalizando os seus impactos nos espaços de trabalho e familiar dos seus usuários, assim como a repercussão das representações acerca das tecnologias sobre as interações ocorridas online e offline. A criação das fronteiras online e off-line também pode ser estudada, já que a constituição dessas fronteiras depende das ações dos participantes da interação (BARROS 2016: p.7).

Em relação aos trabalhos cujas temáticas são mais voltadas para as discussões de gênero, tecnologias médicas e saúde, é possível notar que muitas das pesquisas são empreendidas a partir da observação participante e da etnografia presencial, sobretudo em instituições hospitalares ou redes de apoio diversas, como os trabalhos "Nascer Kalunga, da casa ao hospital: Como as mulheres Kalunga avaliam as diferentes experiências de parto no cenário obstétrico atual?" de Gisele Oliveira Muniz, "Hormonioterapia e a adequação de gênero no processo transexualizador" de Anderson Santos Almeida e o trabalho "Compreensões e papéis da tecnologia no ideário do parto humanizado" de Camila Pimentel, realizado a partir do trabalho de campo em um curso para capacitação sobre parto domiciliar (PIMENTEL 2018).

Algumas pesquisas também foram realizadas a partir de etnografia empreendida tanto nas redes online quanto nas redes offline, como o trabalho "Crianças especiais para famílias especiais': Os sentidos de maternidade para mães de bebês com microcefalia em Pernambuco" de Diego Alano de Jesus Pereira Pinheiro, que trata das vivências e experiências de maternagem das "mães de micro" no grupo UMA (“União Mães de Anjos"), em Recife-PE. O autor pôde acompanhar suas interlocutoras tanto virtual quanto presencialmente, buscando "rastrear e retraçar as intricadas teias de significado e trajetórias de vida dessas mulheres-mães e as formas como elas constroem as noções e representações em torno da maternidade e de como o discurso médico interfere ou não no seu cotidiano" (PINHEIRO 2016: p.3). Outro exemplo interessante é o trabalho "Grupo Papo de Mãe: uma experiência de rede de apoio à maternagem em Belém do Pará”, de Natália Conceição Silva Barros Cavalcanti, em que a autora, além de pesquisadora, é também "nativa" e pôde se inserir no campo justamente por compartilhar da experiência e daquela rede de apoio à maternagem, que surgiu da iniciativa de uma fisioterapeuta buscando reunir as clientes de sua clínica/espaço para gestantes (Academia da Gestante e do Bebê) e divulgar notícias sobre o espaço, responder dúvidas das "alunas". O grupo, segundo a autora, não dependia da fisioterapeuta (administradora do grupo e da clínica) para que as discussões ocorressem, funcionando para que as mães e gestantes pudessem compartilhar uma série de experiências, conselhos, dúvidas etc., tendo extrapolado seu objetivo inicial. 
As relações sociais do grupo de mães aqui analisado se constitui como uma forma típica da contemporaneidade por ter surgido na virtualidade do grupo da Academia da Gestante e do Bebê e posteriormente como Papo de Mãe na rede WhatsApp. Mas, longe do que possamos imaginar, não se trata de relações líquidas, mas da construção cotidiana e efetiva de vínculos, de cuidados com as mães e as crianças. As relações e seus vínculos foram tecidas no tempo do maternar e hoje com uma segunda geração de filhos surgindo na vida de algumas mães do grupo, já podemos afirmar que há uma "família Papo de Mãe", uma "rede de apoio à maternagem” (CAVALCANTI 2016: p.9).

A pesquisa em arquivo também se destacou entre os métodos utilizados, sendo grande parte pesquisas realizadas sobre e a partir de matérias de jornais e revistas (online ou impressos). No trabalho "Lei João W. Nery e Identidade de gênero: as Materialidades do Estado e seus contornos na (Inter)relação entre sexo-gênero-sexualidade" de Lucas Riboli Besen e Gláucia Cristina Maricato Moreto, por exemplo, os autores analisam o Projeto de Lei 5002/2013 (Lei João Nery), bem como outros PLs que tratavam de gênero, orientação sexual, identidade de gênero, etc., desde 1995 (BESEN; MORETO 2015). Outros exemplos são os trabalhos “'Ortopedias' para as 'sexualidades desviantes': teorias e experimentos de terapias de 'reversão sexual' na endocrinologia do início do século XX" de Giulia Bauab Levai, e "Aprimoramento bioquímico e reatualizações de gênero. A promoção das descobertas científicas em torno da ocitocina em veículos de comunicação no Brasil” de Fernanda de Carvalho Vecchi Alzuguir e Fabiola Rohden. De acordo com as autoras,

O foco de investigação reside na divulgação de descobertas científicas em torno da ocitocina em veículos nacionais de comunicação como revistas de grande circulação, jornais, portais de notícias e sites de clínicas, médicos, farmácias de manipulação, laboratórios. Foram ao todo analisadas 68 matérias publicadas entre 1990 e 2015 (ALZUGUIR; ROHDEN 2018).

Cabe também salientar que entre as edições de 2015 e 2017 da ReAct 2015 e de 2016 e 2018 da RBA houve um crescimento significativo do número de trabalhos e GTs. Contudo, corroborando os resultados da etapa anterior do projeto (GONÇALVES 2018), pôde-se constatar um número ainda reduzido de trabalhos que articulam as temáticas de gênero, sexualidade, ciência e tecnologia considerando o universo total de trabalhos e GTs realizados eventos aqui analisados. Ambas as edições da RBA, por exemplo, contam com mais de 60 GTs, e cerca de 20 trabalhos em cada GT. É importante ressaltar que ambos os eventos organizam os temas de seus Seminários Temáticos e Grupos de Trabalho anteriormente à 
submissão dos trabalhos a serem apresentados, o que pode ser um dado relevante no que se refere à quantidade de trabalhos que interseccionam gênero, ciência, sexualidade e tecnologia nesses eventos. Os STs e GTs são propostos por acadêmicos interessados em coordenar as discussões, que, muitas vezes, articulam-se às áreas de pesquisa dos próprios debatedores/coordenadores. Nesse sentido, o baixo número de trabalhos combinado ao baixo número de GTs e também à reduzida quantidade de artigos publicados em revistas brasileiras demonstra um crescimento ainda incipiente dessas discussões num cenário mais amplo, sobretudo em relação às etnografias virtuais/online.

\section{Algumas conclusões}

Considerando que a proposta desta pesquisa era mapear as discussões mais recentes na Antropologia sobre as intersecções entre gênero, sexualidade, ciência e tecnologia por meio dos trabalhos apresentados em edições recentes da ReAct (2015 e 2017) e da RBA (2016 e 2018), buscando problematizar o fazer etnográfico e suas relações com a pesquisa nas redes digitais, foi possível identificar alguns eixos temáticos presentes nos trabalhos e nos Seminários Temáticos/Grupos de Trabalho em ambos os eventos. Temas como maternidade e parturição, hormonização e distinções sexuais, experiências sobre HIV, ciberfeminismo e relações desiguais de gênero e sexualidade na rede, internet como plataforma de mobilização, e outros, foram recorrentes em vários trabalhos.

Ao todo, foram analisados 55 trabalhos em 11 STs/GTs, sendo cinco destes na RBA 2018. É interessante notar que em 2015, na ReAct, foram identificados apenas três trabalhos em um único ST, e em 2017, no mesmo evento, houve dois STs e oito trabalhos. Em 2016, na RBA, foram identificados 19 trabalhos em dois GTs (além do GT052 - "Políticas etnográficas no campo da cibercultura" - que, apesar de não contar com nenhum trabalho sobre gênero e sexualidade naquela edição, é um GT que possibilita a submissão de pesquisas que articulam essas temáticas). Já na RBA 2018, foram apresentados 25 trabalhos em cinco diferentes GTs. Esses dados apontam para um crescimento do número de trabalhos e GTs/STs que interseccionam gênero, ciência, sexualidade e tecnologia a cada edição dos eventos. Nesse sentido, o número de trabalhos e STs/GTs ainda é reduzido, se comparado à quantidade total de STs/GTs e trabalhos apresentados nos eventos, mas observa-se uma tendência crescente.

Em relação às escolhas etnográficas utilizadas nos trabalhos, é interessante observar que, apesar de muitas pesquisas se basearem na observação participante mais clássica, presencial, muitos trabalhos se desenvolveram a partir da etnografia em ambientes digitais. Muitas pesquisas também utilizam da internet como ferramenta de pesquisa, principalmente na busca por artigos, notícias, leis e outras publicações online que sejam in teressantes aos trabalhos. Esse grande número de trabalhos baseados em etnografias online pode ser fruto do crescimento do próprio campo de estudos sobre ciberculturas e ciberativismos, nacionalmente observado em contexto mais amplo. Como já ressaltamos, as discussões sobre plataformas digitais e cibercultura dentro da antropologia têm tido um importante papel no 
debate sobre possibilidades etnográficas e procedimentos teórico-metodológicos. Cabe mencionar que as etnografias realizadas em espaços digitais (seja exclusivamente, seja em conjunto com etnografia presencial) foram mais utilizadas quando o objeto de estudo dos trabalhos era centrado no próprio ciberespaço, como os trabalhos sobre opinião pública e debates nas redes sociais, análise de grupos no Whatsapp e em outros aplicativos/redes sociais, ciberfeminismo e outros movimentos sociais que se utilizam das redes para articulação política, etc. Entre esses trabalhos, vários evidenciam que as oposições online/offline, virtual/material não fazem mais tanto sentido, uma vez que as fronteiras entre essas esferas é dinâmica e se diluem nas interações que se permeiam, afetam e repercutem entre si.

No entanto, pensando os resultados encontrados por Gonçalves (2018) e o número ainda reduzido de trabalhos se comparado ao cenário total da quantidade de pesquisas apresentadas nos quatro eventos analisados, não podemos desconsiderar que ainda há uma certa resistência às etnografias online nas pesquisas de gênero e sexualidade (talvez até na antropologia como um todo), ainda que estejamos caminhando afirmativamente nesse sentido. Por isso, na medida em que rediscutimos a autoridade e o fazer etnográfico e dilatamos a noção de campo nas pesquisas antropológicas de gênero e sexualidade, e que percebemos o quanto as fronteiras entre "online" e "offline", "virtual/material" já não fazem mais tanto sentido sob várias perspectivas, é preciso ter em mente a ampliação desse entendimento para que as etnografias realizadas no ciberespaço sejam plenamente aplicadas e reconhecidas como uma possibilidade tão legítima quanto qualquer outra. Afinal, grupos que se reúnem pessoalmente não se relacionam também a partir de plataformas digitais, como Facebook ou Whatsapp, por exemplo? Como as plataformas online são importantes na vida de nossos interlocutores? Quais relações estamos deixando de observar enquanto etnógrafos ao não considerar essas interações online? Sendo essas relações tão válidas quanto aquelas realizadas pessoalmente, o quanto isso pode agregar ao conhecimento que temos acerca dessas pessoas? À nossa pesquisa, à nossa etnografia? Talvez expandir (ou derrubar) cada vez mais essas fronteiras seja um movimento que amplia nossas possibilidades de apreensão etnográfica e, com certeza, tem muito a acrescentar ao conhecimento antropológico.

\section{Referências Bibliográficas}

30a REUNIÃO BRASILEIRA DE ANTROPOLOGIA. (2016). Grupo de Trabalho. Disponível em: <http://evento.abant.org.br/rba/30rba/?CONTEUDO=8>. Acesso em jul. 2019.

31 a REUNIÃO BRASILEIRA DE ANTROPOLOGIA. (2018). Grupos de Trabalho. Disponível em: <http://www.evento.abant.org.br/rba/31RBA/GT>. Acesso em jul. 2019.

ALZUGUIR, Fernanda de Carvalho Vecchi; ROHDEN, Fabiola. (2018). Aprimoramento bioquímico e reatualizações de gênero. A promoção das descobertas científicas em torno 
da ocitocina em veículos de comunicação no Brasil. Anais da 31ª Reunião de Antropologia Brasileira. Brasília.

ASSOCIAÇÃO BRASILEIRA DE ANTROPOLOGIA. (2019). Histórico. Disponível em: $<$ http://www.portal.abant.org.br/historico/>. Acesso em jul. 2019.

BARROS, Zelinda dos Santos. (2016). Interseção de gênero e raça num território privativo do ciberespaço. Anais da 30a Reunião Brasileira de Antropologia. João Pessoa-PB.

BESEN, Lucas Biboli; MORETO, Gláucia Cristina Maricato. (2015). Lei João W. Nery e Identidade de gênero: as Materialidades do Estado e seus contornos na (Inter)relação entre sexo-gênero-sexualidade. Anais da V Reunião de Antropologia Brasileira. Porto Alegre-RS.

CAVALCANTI, Natália Conceição Silva Barros. (2016). Grupo Papo de Mãe: uma experiência de rede de apoio à maternagem em Belém do Pará. Anais da 30a Reunião de Antropologia Brasileira. João Pessoa-PB.

CLIFFORD, James. (2002). "Sobre a autoridade etnográfica”. In: CLIFFORD, James. A experiência etnográfica: Antropologia e literatura no século XX. (Tradução de Patrícia Farias). Rio de Janeiro: Editora UFRJ, p. 17-62.

FILHO, Ricardo Andrade Coitinho. (2017). O parentesco conformado na experiência soropositiva: Uma abordagem antropológica sobre a transmissão vertical para o HIV na perspectiva crítica dos estudos de gênero. Anais da VI Reunião de Antropologia da Ciência e Tecnologia. São Paulo-SP.

GONÇALVES, Ítalo Vinícius. (2018). O/A antropólogo/a no campo e na rede: o fazer etnográfico em pesquisas de gênero e sexualidade. Relatório Final de Iniciação Científica. Belo Horizonte: UFMG.

GRILLO, Oscar. (2019). Itinerarios de la antropología y su mirada sobre el mundo digital. In: RIVOIR, Ana L.; MORALES, María J. (coord.). Tecnologías digitales Miradas críticas de la apropiación en América Latina. Buenos Aires: CLACSO, p. 21-34.

HARAWAY, Donna. (1995). Saberes Localizados: a questão da ciência para o feminismo e o privilégio da perspectiva parcial. Cadernos Pagu, n.5, p. 7-41.

HINE, Christine. (2004). Introducción. In: HINE, Christine. Etnografía Virtual. Barcelona: Editorial UOC, p. 9-24.

LEITÃO, Debora K., GOMES, Laura G. (2017). Etnografia em ambientes digitais: perambulações, acompanhamentos e imersões. Revista Antropolítica, n.42, p. 41-61. DOI https://doi.org/10.22409/antropolitica2017.1i42.a546

LEVAI, Giulia Bauab. (2018). “Ortopedias" para as "sexualidades desviantes": teorias e experimentos de terapias de "reversão sexual" na endocrinologia do início do século XX. Anais 31ª Reunião de Antropologia Brasileira. Brasília.

LINS, Beatriz Accioly. (2016). Vazou na internet: gênero, violência e internet nos debates sobre 'pornografia de vingança'. Anais da 30a Reunião Brasileira de Antropologia. João Pessoa-PB. 
LIMA, Elizabeth Christina de Andrade. (2016). A Construção da Imagem Pública de Dilma Rousseff no Ciberespaço: Misoginia, estereótipos e relações de gênero. Anais da 30a Reunião Brasileira de Antropologia. João Pessoa-PB.

LOPES, Maria M.; SOMBRIO, Mariana M. (2017). Apresentação. Cadernos Pagu, n. 49, p. 1-17. DOI http://dx.doi.org/10.1590/18094449201700490005.

MILLER, Daniel; SLATER, Don. (2004). Etnografia on e off-line: cibercafés em Trinidad. Horizontes Antropológicos. Porto Alegre-RS, v. 10, n. 21, p. 41-65. DOI https://doi.org/10.1590/S0104-71832004000100003

MONTEIRO, Marko S. Alves. (2012). Reconsiderando a Etnografia da Ciência e da Tecnologia: Tecnociência na prática. Revista Brasileira de Ciências Sociais, v. 27, n.79, p. 139-151. DOI https://doi.org/10.1590/S0102-69092012000200009

NUCCI, Marina Fisher. (2015a). Não chore, pesquise!' - Reflexões sobre sexo, gênero e ciência a partir do neurofeminismo. Tese de Doutorado. Programa de Pòs-Graduação em Saúde Coletiva. Rio de Janeiro: Universidade Estadual do Rio de Janeiro, 2015a.

NUCCI, Marina Fisher. (2015b). 'Não chore, pesquise!' - Reflexões sobre sexo, gênero e ciência a partir do neurofeminismo. Anais da V Reunião de Antropologia da Ciência e Tecnologia. Porto Alegre-RS.

PEIRANO, Mariza. (2014). Etnografia não é método. Horizontes Antropológicos, ano 20, n. 42. Porto Alegre, p. 377-391. DOI http://dx.doi.org/10.1590/S010471832014000200015

PINHEIRO, Diego Alano de Jesus. (2016). “Crianças especiais para famílias especiais”: Os sentidos de maternidade para mães de bebês com microcefalia em Pernambuco. Anais da 30a Reunião de Antropologia Brasileira. João Pessoa-PB.

PIMENTEL, Camila. (2018). Compreensões e papéis da tecnologia no ideário do parto humanizado. 31ª Reunião de Antropologia Brasileira. Brasília.

REUNIÃO DE ANTROPOLOGIA DA CIÊNCIA E TECNOLOGIA. (2019). Anais da ReACT - Reunião de Antropologia da Ciência e Tecnologia 2014-2019. Disponível em: $<$ https://ocs.ige.unicamp.br/ojs/react/issue/archive>. Acesso em jul. 2019.

ROHDEN, Fabíola; MONTEIRO, Marko. (2019). Para além da ciência e do anthropos: deslocamentos da antropologia da ciência e da tecnologia no Brasil. Revista Brasileira de Informação Bibliográfica em Ciências Sociais - BIB, n. 89, p. 1-33. DOI 10.17666/bib8907/2019

SEGATA, Jean; RIFIOTIS, Theophilos. (2016). Antropologia e Cibercultura. In: SEGATA, Jean; RIFIOTIS, Teophilos. (org.). Politicas Etnográficas no Campo da Cibercultura. Brasília: ABA Publicações, p. 9-20.

TRAMONTANO, Lucas. (2017). 'Corpo de monstro, mente de cientista': contradições nos discursos médicos e leigos acerca do uso da testosterona como anabolizante muscular. Anais da VI Reunião de Antropologia da Ciência e Tecnologia. São Paulo-SP. 
sobre as autoras

\section{Júlia Vargas Batista}

Graduanda em Antropologia com habilitação em Antropologia Social pela Universidade Federal de Minas Gerais. Membro do Grupo de Estudos em Gênero e Sexualidade (GESEX), vinculado ao Departamento de Antropologia e Arqueologia (DAA) da UFMG. Atualmente é bolsista de Iniciação Científica do Instituto René Rachou Fiocruz Minas Gerais.

\section{Érica Renata de Souza}

Professora Associada do Departamento de Antropologia e Arqueologia (DAA) e do Programa de Pós-Graduação em Antropologia, ambos da Universidade Federal de Minas Gerais (UFMG). Doutora em Ciências Sociais pela Universidade Estadual de Campinas (UNICAMP, 2005), com doutorado-sanduíche na York University, Toronto, Canadá (2002).

Recebido em 29/09/2020 Aceito para publicação em 04/12/2020 


\section{Documento Suplementar Trabalhos identificados por evento e ST/GT}

ReAct 2015:

\begin{tabular}{|l|l|l|}
\hline ST 8 - Corporalidades, Saberes e tecnologias \\
\hline Janaína Freitas & $\begin{array}{l}\text { Intersexualidades e Biotecnologias: um estudo } \\
\text { antropológico acerca da inserção da Hiperplasia Adrenal } \\
\text { Congênita no Teste do Pezinho" }\end{array}$ \\
\hline Marina Fisher Nucci & $\begin{array}{l}\text { Não chore, pesquise! - Reflexões sobre sexo, gênero e } \\
\text { ciência a partir do neurofeminismo }\end{array}$ \\
\hline $\begin{array}{l}\text { Lucas Riboli Besen, } \\
\begin{array}{l}\text { Gláucia Cristina João W. Nery e Identidade de gênero: as } \\
\text { Maricato Moreto }\end{array}\end{array}$ & $\begin{array}{l}\text { Materialidades do Estado e seus contornos na } \\
\text { (Inter)relação entre sexo-gênero-sexualidade }\end{array}$ \\
\hline
\end{tabular}

ReAct 2017:

ST 8 - (Co)produções contemporâneas: Intervenções biotecnológicas sobre o corpo, gênero e sexualidade

\begin{tabular}{|l|l|}
\hline $\begin{array}{l}\text { Anderson Santos } \\
\text { Almeida }\end{array}$ & $\begin{array}{l}\text { Hormonioterapia e a adequação de gênero no processo } \\
\text { transexualizador }\end{array}$ \\
\hline $\begin{array}{l}\text { Regina Senna Vieira e } \\
\text { Miriam Oliveira } \\
\text { Mariano }\end{array}$ & Corpo hormonal feminino e suas fases \\
\hline $\begin{array}{l}\text { Ricardo Andrade } \\
\text { Coitinho Filho }\end{array}$ & $\begin{array}{l}\text { O parentesco conformado na experiência soropositiva: } \\
\text { Uma abordagem antropológica sobre a transmissão } \\
\text { vertical para o HIV na perspectiva crítica dos estudos de } \\
\text { gênero }\end{array}$ \\
\hline $\begin{array}{l}\text { Felipe Cavalcanti } \\
\text { Ferrari }\end{array}$ & $\begin{array}{l}\text { Entre revoluções sexuais e ferramentas de prevenção: } \\
\text { uma narrativa sobre a emergência da Profilaxia Pré- } \\
\text { Exposição (PrEP)" }\end{array}$ \\
\hline Lucas Tramontano & $\begin{array}{l}\text { "Corpo de monstro, mente de cientista": contradições nos } \\
\text { discursos médicos e leigos acerca do uso da testosterona } \\
\text { como anabolizante muscular }\end{array}$ \\
\hline $\begin{array}{l}\text { Georgia Pereira e e } \\
\text { Rogerio Lopes Azize }\end{array}$ & $\begin{array}{l}\text { Não afeta a libido!: reflexões sobre hormônios e a } \\
\text { construção da viabilidade de contraceptivos masculinos }\end{array}$ \\
\hline
\end{tabular}

\section{ST 17 - Políticas etnográficas no campo da cibercultura}

Andrey Felipe Sgorla Gênero e mercado de cervejas artesanais: percursos, recursos e estratégias de empresirilização de si

Tauana Mariana "Reflexões iniciais sobre o projeto 'Livros, literatura e Weinberg Jeffman empoderamento feminino: um estudo etnográfico sobre o projeto Leia Mulheres nas redes sociais'

RBA 2016:

\section{GT 10 - Antropologia Digital, Tecnologia e Cibercultura}

\begin{tabular}{|l|l|}
\hline Ana Paula Vencato & $\begin{array}{l}\text { Gênero e sexualidade em tempos instáveis: mídias } \\
\text { digitais, identificações e conflitos }\end{array}$ \\
\hline Beatriz Accioly Lins & $\begin{array}{l}\text { Vazou na internet: gênero, violência e internet nos } \\
\text { debates sobre 'pornografia de vingança' }\end{array}$ \\
\hline $\begin{array}{l}\text { Elizabeth Christina de } \\
\text { Andrade Lima }\end{array}$ & $\begin{array}{l}\text { A Construção da Imagem Pública de Dilma Rousseff no } \\
\text { Ciberespaço: Misoginia, estereótipos e relações de gênero }\end{array}$ \\
\hline
\end{tabular}




\begin{tabular}{|l|l|}
\hline $\begin{array}{l}\text { Mario Felipe de Lima } \\
\text { Carvalho }\end{array}$ & $\begin{array}{l}\text { "Amanhã vai ser maior" (?): notas sobre os usos da } \\
\text { internet nos (in)sucessos de duas manifestações de rua } \\
\text { do ativismo de pessoas trans }\end{array}$ \\
\hline $\begin{array}{l}\text { Sheila Cavalcante dos } \\
\text { Santos }\end{array}$ & $\begin{array}{l}\text { "Meu Tinder tá bombando!": Geolocalização, sociabilidade } \\
\text { e vivências da sexualidade }\end{array}$ \\
\hline $\begin{array}{l}\text { Zelinda dos Santos } \\
\text { Barros }\end{array}$ & $\begin{array}{l}\text { Interseção de gênero e raça num território privativo do } \\
\text { ciberespaço }\end{array}$ \\
\hline Carolyna Kyze Melo & $\begin{array}{l}\text { Caiu na rede: reflexões sobre casos de pornografia de } \\
\text { revanche no Brasil (pôster) }\end{array}$ \\
\hline
\end{tabular}

\begin{tabular}{|l|l|}
\hline \multicolumn{2}{|l|}{ GT 049 - Partos e/ou maternidades e políticas do corpo: perspectivas antropológicas } \\
\hline $\begin{array}{l}\text { Amanda Bartolomeu } \\
\text { Santos }\end{array}$ & $\begin{array}{l}\text { A produção do aleitamento materno: recursos } \\
\text { biomédicos, corpos e gêneros }\end{array}$ \\
\hline Clara Cazarini Trotta & \#MaternidadeReal: conteúdo impróprio \\
\hline Juliara Borges Segata & $\begin{array}{l}\text { Mães em rede: experiências de gravidez, parto e } \\
\text { puerpério em um grupo de gestantes no whatsapp }\end{array}$ \\
\hline Gisele Oliveira Muniz & $\begin{array}{l}\text { Nascer Kalunga, da casa ao hospital: Como as mulheres } \\
\text { Kalunga avaliam as diferentes experiências de parto no } \\
\text { cenário obstétrico atual?" }\end{array}$ \\
\hline $\begin{array}{l}\text { Érica Dumont Pena e e } \\
\text { Rogério Correia }\end{array}$ & $\begin{array}{l}\text { Nascer Xakriabá: técnicas do corpo e cuidado antes e } \\
\text { após o nascimento }\end{array}$ \\
\hline Elaine Müller & $\begin{array}{l}\text { O desafio da maternidade': protagonismo feminino para } \\
\text { além do parto }\end{array}$ \\
\hline $\begin{array}{l}\text { Natália Conceição Silva } \\
\text { Barros Cavalcanti }\end{array}$ & $\begin{array}{l}\text { Grupo Papo de Mãe: uma experiência de rede de apoio à } \\
\text { maternagem em Belém do Pará }\end{array}$ \\
\hline $\begin{array}{l}\text { Diego Alano de Jesus } \\
\text { Pereira Pinheiro }\end{array}$ & $\begin{array}{l}\text { Crianças especiais para famílias especiais': Os sentidos de } \\
\text { maternidade para mães de bebês com microcefalia em } \\
\text { Pernambuco }\end{array}$ \\
\hline $\begin{array}{l}\text { Jaqueline Cardoso } \\
\text { Portela }\end{array}$ & $\begin{array}{l}\text { Não me obriguem a um parto normal': Concepções de } \\
\text { corpo e direito de escolha de mulheres gestantes que } \\
\text { optam pela cesárea eletiva }\end{array}$ \\
\hline Sara Sousa Mendonça & \begin{tabular}{l} 
Por que o parto se tornou uma questão? \\
\hline $\begin{array}{l}\text { Lidiane Mello de Castro } \\
\text { e Edemilson Antunes } \\
\text { de Campos }\end{array}$
\end{tabular} $\begin{array}{l}\text { Múltiplas faces de um conceito de parto: uma abordagem } \\
\text { etnográfica de grupos do Movimento de Humanização do } \\
\text { Parto e Nascimento }\end{array}$ \\
\hline Camila Castello & $\begin{array}{l}\text { Exercícios para o trabalho de parto: roda de conversa para } \\
\text { mulheres grávidas, doulas e acompanhantes - Um ensaio } \\
\text { fotográfico (pôster) }\end{array}$ \\
\hline
\end{tabular}

\section{RBA 2018:}

\begin{tabular}{|c|c|}
\hline Bruna Klöppel & $\begin{array}{l}\text { Os hormônios contraceptivos entre antigas e novas } \\
\text { controvérsias: (re)negociações em torno de } \\
\text { contracepção, gênero e saúde }\end{array}$ \\
\hline $\begin{array}{l}\text { Fernanda de Carvalho } \\
\text { Vecchi Alzuguir e } \\
\text { Fabíola Rohden }\end{array}$ & $\begin{array}{l}\text { Aprimoramento bioquímico e reatualizações de gênero. } \\
\text { A promoção das descobertas científicas em torno da } \\
\text { ocitocina em veículos de comunicação no Brasil }\end{array}$ \\
\hline - Flora Villas Carvalho & $\begin{array}{l}\text { Encriptando denúncias e revelando opressões: a internet } \\
\text { enquanto plataforma para denúncias de violências de } \\
\text { gênero e a agenda ciberfeminista (pôster) }\end{array}$ \\
\hline Gabriela Cabral Paletta & $\begin{array}{l}\text { Menstruapps e possíveis interseções entre corpo, } \\
\text { tecnologia, política e gênero }\end{array}$ \\
\hline Lucas Tramontano & $\begin{array}{l}\text { A testosterona faz mal? Reflexões antropológicas sobre o } \\
\text { uso masculino de um hormônio }\end{array}$ \\
\hline
\end{tabular}




\begin{tabular}{|c|c|}
\hline Alessandra Brigo & Etnografias abortivas na cidade de Belo Horizonte" \\
\hline $\begin{array}{l}\text { Ana Claudia Coutinho } \\
\text { da Silva e Cintía de } \\
\text { Souza Batista Tortato }\end{array}$ & $\begin{array}{l}\text { As Vozes que gritam tem cor: Violência Obstétrica e o } \\
\text { Impacto na vida das Mulheres Negras }\end{array}$ \\
\hline $\begin{array}{l}\text { Antônio } \quad \text { Ricardo } \\
\text { Ximenes de Araújo }\end{array}$ & $\begin{array}{l}\text { Mediação e moralidades sobre medicamentos de gênero: } \\
\text { A implementação das Profilaxias Pré-Exposição ao HIV } \\
\text { num hospital da rede pública do Natal-RN }\end{array}$ \\
\hline Elaine Reis Brandão & $\begin{array}{l}\text { Contracepção no Brasil: biopolítica e moralidades em } \\
\text { jogo }\end{array}$ \\
\hline $\begin{array}{l}\text { Eliana Coelho da Silva e } \\
\text { Alba Maria Pinho de } \\
\text { Carvalho }\end{array}$ & $\begin{array}{l}\text { Nem Presa, Nem morta': } \mathrm{O} \text { debate sobre a } \\
\text { descriminalização do aborto nas redes sociais durante a } \\
\text { audiência pública no STF da ADPF } 442\end{array}$ \\
\hline Giulia Bauab Levai & 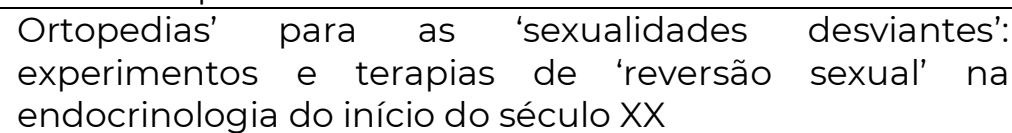 \\
\hline $\begin{array}{ll}\text { Jonatan } & \text { Jackson } \\
\text { Sacramento e Maria } \\
\text { Conceição da Costa }\end{array}$ & $\begin{array}{l}\text { Gênero e saúde em contexto de duplo fazer: as respostas } \\
\text { ao Zika vírus no Brasil }\end{array}$ \\
\hline Rozeli Maria Porto & $\begin{array}{l}\text { Zika Vírus e Síndromes Congênitas: Impacto da Epidemia } \\
\text { em Mulheres 'Mães de Micro' no RN em um contexto pós- } \\
\text { golpe }\end{array}$ \\
\hline $\begin{array}{l}\text { Sandra } \\
\text { Teixeira }\end{array}$ & $\begin{array}{l}\text { Gênero, Saúde e Direitos Sexuais e Reprodutivos: Uma } \\
\text { Análise da Lei } 9.263 / 96 \text { e a Questão do Aborto: Desafios e } \\
\text { Estratégias de Enfrentamento para a Efetivação das } \\
\text { Políticas Públicas }\end{array}$ \\
\hline
\end{tabular}

\begin{tabular}{|c|c|}
\hline $\begin{array}{l}\text { Asher Grochowalski } \\
\text { Brum Pereira }\end{array}$ & $\begin{array}{l}\text { Espiritualidade, subjetividade e doença: experiências } \\
\text { com o HIV }\end{array}$ \\
\hline $\begin{array}{l}\text { Vera Lucia Marques da } \\
\text { Silva }\end{array}$ & $\begin{array}{l}\text { Um olhar acerca das relações eróticas de dominação e } \\
\text { submissão no BDSM sob a perspectiva de gênero }\end{array}$ \\
\hline $\begin{array}{l}\text { Camilo } \\
\text { de Braz }\end{array}$ & $\begin{array}{l}\text { Aqui eu sou um cara normal' - narrativas sobre espera e } \\
\text { acesso a direitos entre homens trans na Argentina }\end{array}$ \\
\hline
\end{tabular}

\begin{tabular}{|c|c|}
\hline Camila Pimentel & $\begin{array}{l}\text { Compreensões e papéis da tecnologia no ideário do parto } \\
\text { humanizado }\end{array}$ \\
\hline Marina Fisher Nucci & 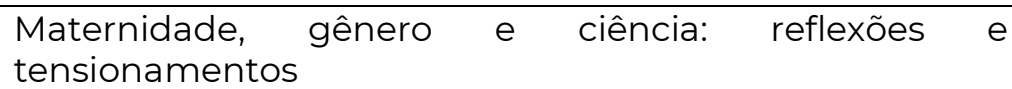 \\
\hline \begin{tabular}{lcr} 
Obonyo & Meireles da \\
Guerra, & \multicolumn{2}{c}{ Clotildes } \\
Martins & Morais e \\
Esmael & Alves de \\
Oliveira & &
\end{tabular} & $\begin{array}{l}\text { Quando corpo, gênero e saúde se encontram: algumas } \\
\text { reflexões sobre os Itinerários Terapêuticos da Infertilidade } \\
\text { Feminina no contexto moçambicano }\end{array}$ \\
\hline $\begin{array}{lcc}\text { Violeta } & \text { Sarai } & \text { Salazar } \\
\text { Salazar } & \text { e } & \text { Raquel } \\
\text { Wiggers } & & \end{array}$ & $\begin{array}{l}\text { Mães, falemos de maternidade'. Estudo etnográfico da } \\
\text { maternidade }\end{array}$ \\
\hline
\end{tabular}


GT 057 - Processos e dinâmicas no ciberespaço: divergências, dissidências, usos e contra-usos em relação à experiência de si

\begin{tabular}{|l|l|}
\hline $\begin{array}{l}\text { Fabiana Jordão } \\
\text { Martinez }\end{array}$ & $\begin{array}{l}\text { Ontologias feministas no ciberespaço: discursos e contra } \\
\text { discursos 'radfem' }\end{array}$ \\
\hline $\begin{array}{l}\text { Fernanda Cristina } \\
\text { Ferreira Nunes }\end{array}$ & $\begin{array}{l}\text { Tour pelo meu corpo': narrativas de mulheres com } \\
\text { deficiência no YouTube }\end{array}$ \\
\hline Márcia Mesquita & $\begin{array}{l}\text { Notas de campo: a maquiagem como construção de um } \\
\text { rosto }\end{array}$ \\
\hline Marcella Uceda Betti & $\begin{array}{l}\text { Influenciadoras digitais crespas e cacheadas: plataformas } \\
\text { online, mercado e produção de subjetividades }\end{array}$ \\
\hline
\end{tabular}

